\title{
Conclusion - Building Regions from Below: Has the Time Come for Regionalism 2.0?
}

\section{Lorenzo Fioramonti}

In a changing world ridden with crises and characterised by a general redistribution of power, regional organisations need to reinvent themselves. Equally, the study of regionalism has to reject its traditional Eurocentrism to embrace new conceptual categories in order to describe more effectively the variety of regional processes across the world. Against this background, this article looks at the European project and its current crisis before dis-cussing other regional 'experiments' in Africa, Asia and Latin America, which rest on different principles but also manifest considerable shortcom-ings. The analysis points to the need to look at regionalism with a critical eye, emphasizing the undeniably important achievements but also the hidden threats that a certain model of regional integration (for instance, the classical top-down elite-driven process adopted by the EU founding fathers) can pose to the sustainability of regional cohesion and the adapt-ability of this model to other areas of the world.

Keywords: Regionalism 2.0, comparative analysis, new models, Eurocentrism, citizen-driven governance

In a changing world, where old and new developments challenge traditional decision making and (nation) states find it increasingly difficult to govern political and economic processes that are ever more cross-boundary in nature, regional governance has become a powerful tool to address such growing complexity. As a meso-level between the state and the international system, regional organisations have been purposely created to deal with phenomena and processes transcending the borders of national communities. Nowadays, there is a virtually endless list of regional organisations operating in various sectors, entrusted with varying degrees of power and decision-making authority. Although most of them perform only specific functions (e.g. natural resources management, conflict prevention, legal advice, customs

Lorenzo Fioramonti is Associate Professor at the University of Pretoria (South Africa). Thanks go to Luk Van Langenhove from whom the 2.0 metaphor has been borrowed, and who has adopted it to describe the evolution of multilateralism. Email: lorenzo.fioramonti@gmail.com 
control, policing, etc.), there has been an increase in 'general purpose' regional organisations, of which the European Union (EU) is the most well known and developed. Some of them, such as the Common Market of the South (Mercosur), have evolved out of specific trade agreements (e.g. free trade areas), while others, such as the Association of South East Asian Nations (ASEAN) and the African Union (AU) have been created with a view to guaranteeing security and development. As famously remarked by Peter Katzenstein, the contemporary international arena may very well develop into a 'world of regions', where openness and cooperation are reinforced by growth in cross-border exchanges and interstate relations. ${ }^{1}$

Along with the mushrooming of regional organisations, the study of regionalism has also evolved. While the concept was simply subsumed under the broader field of international relations (often as a sub-category like economic interdependence) until the 1980s, since the end of the Cold War a renewed focus on the role of regional organisations has given birth to a specific field of study, which highlights the increasing complexity of regional formations and their multi-level/multisectoral purposes. ${ }^{2}$ A wealth of comparative analyses and in-depth case studies have thus shown the ambivalence of concepts such as 'cooperation' and 'integration', traditionally considered elements of a continuum of economic regionalisation. While the term regional cooperation is now broadly employed to describe the numerous cases of structured collaboration among governments in a given geographic area, regional integration describes the process of supranationalisation of authority in a given policy field, which requires some degree of shared sovereignty.

More recently, a 'new' regionalism approach has produced important insights into the study of regional politics and has also emphasized the peculiarities of regionalism beyond the traditional European context. ${ }^{3}$ While the debate on regionalism was long dominated by EU scholars, which led to theories unable to 'travel well' and continuous claims of European 'exceptionalism', several attempts have recently been made to compare regionalism across regions in order to highlight mutual learning and specific trends. ${ }^{4}$ Most scholars of regionalism today would have no problem accepting that regionalism is not the monopoly of states but also encompasses interactions among non-state actors, as well as between states and non-state actors within a given policy area. Moreover, it is generally understood now that regionalism is somewhat different from regionalisation, which usually describes the intensity of economic interdependence and can be exclusively market driven rather than political/institutional. There is also increasing recognition, by and large prompted by the application of constructivism to the study of regionalism, that regions are not a geographic given, but are socially constructed through

\footnotetext{
${ }^{1}$ Katzenstein, A World of Regions.

${ }^{2}$ Fawcett, "Regionalism in Historical Perspective".

${ }^{3}$ Warleigh-Lack et al., New Regionalism and the European Union.

${ }^{4}$ Ibid.
} 
human interactions, political discourse and cultural evolutions. ${ }^{5}$ This has emphasized the role of domestic and transnational factors, which are important determinants in the emergence and development of regional institutions, and has increasingly contributed to understanding regionalism as a political process.

This concluding article looks at the process of regionalism from a global perspective and builds on the various contributions of this issue. References will be made to the European project and its current crisis before discussing other regional 'experiments' in Africa, Asia and Latin America, which rest on different principles but also manifest considerable shortcomings. This essay will also discuss the need to look at regionalism with a critical eye, pointing out the undeniably important achievements but also the hidden threats that a certain model of regional integration (for instance, the classical top-down elite-driven process adopted by the EU founding fathers) can pose to the sustainability of regional cohesion and the adaptability of this model to other areas of the world. Finally, this analysis will reflect on the future of regionalism in a changing world by pointing to the need to build regions 'from below'.

\section{The end of Eurocentrism? Research, ideas and crises}

In the opening contribution to this issue, Amitav Acharya argues that the eurocentric approach to the study of regionalism "is being seriously questioned" by many European scholars and their non-Western colleagues interested in redefining and broadening the scope and tools of enquiry. By drawing attention to the classic distinction between regional cooperation and integration, Acharya advocates a broader and more all-encompassing term such as "regionalism". According to his analysis, "integration studies have always been heavily influenced by the EU's history and experience. The founding theories of integration studies [...] were heavily drawn from the early life of what we call the EU today. By contrast, [...] regionalism has a much more diverse beginning and a global heritage than regional integration and comparative regional integration studies." For Acharya, regional integration is a distinctively Western European idea with little applicability outside of Europe, while the principles of regionalism have a much older origin and have been enriched by contributions from many regions, including Africa, Asia, Latin America and the Middle East.

Luk Van Langenhove builds on Acharya's reflections concerning eurocentrism in the study and practice of regionalism by pointing out that an important element in the debate regarding the epistemological maturity of comparative regional integration studies has been the role played by the EU itself, "which has not only been an object of research but also a rather active subject". After referring to a number of critiques of the EU's hegemonic stance in comparative regional integration studies,

\footnotetext{
${ }^{5}$ Van Langenhove, Building Regions.
} 
which according to some have often been no more than the translation of a particular set of European experiences into more abstract theoretical language, Langenhove proposes to distinguish between "region building" processes, projects and products as a more productive strategy to overcome eurocentrism and strengthen comparative research.

In a similar vein, Peter Draper reflects on the applicability of the European model to the African context and concludes that the latter should break away from the cultural and institutional influence of the EU and find its own way to region building, even though this may mean regionalism on a smaller scale and only limited cooperation in selective fields, especially trade. Given a number of fundamental differences and development-related processes, Draper believes that "a different approach may be more appropriate than formal, EU-style, institutional integration". Furthermore, he warns against a simplistic application of the European model, given that "regional economic integration is not a panacea for African states". While the European "model" may be useful as an aspiration, its unique geopolitical foundations, complex governing institutions and elaborate coordination mechanisms make it rather unfit for the needs of African political economies.

Besides a number of theoretical criticisms, there are also practical (political) reasons why the European model seems increasingly inadequate to describe the evolution of regionalism across the world. The emergence of new centres of power in Asia and Latin America has largely occurred at the expense of the traditional influence exerted by Europe, especially in Africa. This has been coupled with a general weakening of the $\mathrm{EU}$ and its member states in the major international forums, from the World Trade Organisation to the United Nations' conferences on climate change, where European interests and agendas have often been marginalised. Moreover, the EU's current sovereign debt crisis (commonly dubbed 'euro crisis') is likely to further weaken the appeal that integration à la EU has traditionally enjoyed in other countries, especially in the developing world. According to Henk Overbeek, "the debate on the European sovereign debt crisis is inward looking, largely ignoring the global context in which the future of the European project will be decided". Although there is clear evidence that, at least in purely financial terms, most emerging powers like China and Brazil still look at the euro as a valuable international reserve currency (as an alternative to the dollar), the risk is that shortsighted policies and a tendency to rely on technocratic decision-making processes may end up pulling the EU apart or simply relegate it to a minor role in global affairs: "it would then become a magnet for wealthy rentiers and rich tourists from Asia and the Americas, rather than one of the leading powers in the post-crisis world order".

\section{The state of regionalism beyond Europe}

If Europe is increasingly losing its appeal and 'soft power' vis-à-vis new global tendencies, what is the state of regionalism on other continents? The picture 
painted by the contributors to this issue emphasizes a growing diversity of competitive models against the backdrop of rising expectations that may very well go unmet. By reviewing the track record of legal harmonisation in Africa, Magnus Killander concludes that "despite the lofty ambitions set out in the founding treaties of many African regional organisations, little has so far been achieved". The main regional economic communities still have "a long way to go" before reaching the objectives set out in the treaties and "will need to work harder to ensure that shared norms are actually implemented on the ground". The AU, the largest regional organisation on the continent, "has been relatively absent from legal harmonisation efforts apart from the adoption of treaties". Looking at Latin America, Andrés Malamud and Gian Luca Gardini argue that although "regionalism has not delivered", it nevertheless features at the top of the regional political agenda. In their view, the Latin American way of regionalism has been fundamentally hegemonised by the regions' executives (specifically, by incumbent presidents), who continuously refer to vague notions of regional integration to achieve a varying "set of political objectives", including international visibility, regional stability and regime legitimacy, "as well as to please domestic and foreign audiences and mobilise support for the incumbent administrations". With such a variety of national goals, it is hardly surprising that regionalism in Latin America lacks a lead country (for instance, the authors consider Brazil "a lukewarm wouldbe leader" that has not yet been willing to take the responsibility of leading a coherent regional project) and that no minimum common denominator is identifiable either politically or economically across Latin America. They conclude that, if "regionalism remains purely a question of foreign policy then regional organisations can be viewed as cumulative layers of contending national strategies".

In a similar vein, David Camroux wonders whether Asian regional integration has not become "a little like Saint Augustine's chastity, something to be prayed for, but not quite yet". In his view, even finding a conception of an Asian region that "reconciles economic imperatives with underlying geopolitical concerns while being able to generate a sense of identification continues to be an elusive task". His conclusion is that regionalism is not indeed an objective per se on the continent: rather it conceals an overriding quest for pan-Asian (and Asia-Pacific) multilateralism and cooperation, driven by the disparate agendas of regional and global powers, particularly China. The global economic crisis has indeed accelerated this tendency, especially through the "virtual emergence" of a G2 composed of China and the United States, which has resulted in a new injection of life into the Asia-Pacific multilateral project which, only a few years ago, was considered largely superseded by the East Asian regionalisation project.

Echoing Malamud and Gardini's analysis of Latin American regionalism, Draper underlines how strong leadership at the presidential level has so far been the most significant propulsive factor behind cooperation in Africa. Although this has been 
necessary due to the lack of initiative on the part of regional institutions, it invariably "runs the risk of creating a democratic deficit that, in turn, may undermine good governance and potentially the integration scheme itself'. Since democratic or liberal governance has relatively shallow roots across the continent, presidential prerogatives may easily lead to conflicting projects and priorities, as has often been the case not only at the AU level, but also within the various (and overlapping) regional economic communities.

After analysing the role played by regional organisations during the 2011 'Arab spring' in North Africa, Marco Pinfari draws a distinction between the involvement and impact of the Arab League, the AU and the EU in the crisis scenarios. He argues that, as a whole, the North African 'revolutions' showed some encouraging developments for those who, in academia as well as in active politics, "look forward to regional organisations playing an active role in the management of political and military crises". Especially as the momentum of the Arab spring intensified, many major actors called for regional organisations active in the region to assume a central position and 'lead' the international community in the management of these epochal shifts in the Mediterranean: this resulted in a series of "interregional and multilateral initiatives that has few parallels in recent years" as well as "the creation of two ad hoc committees designed to tackle the most complex crisis", that is, the Libyan civil war. In his view, these events "represent a stark rupture with the markedly unilateral or bilateral approach vis-à-vis the Arab world typical of the years that immediately followed the 9/11 attacks, and can be considered a welcome step towards the creation of more inclusive systems of multilateral governance".

At the same time, Pinfari finds that the "actual impact of regional organisations on the development of these revolutions" has been much less pronounced than one would expect. A case in point is that of the AU, which is founded on the principle of "non-interference by any member state in the internal affairs of another". The Union is given the right to intervene only in "grave circumstances", such as war crimes, genocide and crimes against humanity, which partly explains why it remained largely inactive during, for instance, the Tunisian revolution. At the time of Egypt's revolts, the AU intentionally avoided discussing what political stance to take towards the Mubarak regime and, finally, when the crisis in Libya broke out, decided not to support the international contact group and instead "created its own independent Committee, whose impact on the Libyan conflict is still unclear". With regard to the Arab League, Pinfari highlights institutional deficiencies and personal political agendas as key undermining factors. Although the head of the League, Amr Moussa, was particularly vocal against the Egyptian regime's repression of peaceful protests, it is difficult to know whether he "was acting primarily as an Arab League official or as a prospective candidate for Egypt's presidency", having made himself available to lead the opposition to Mubarak. 
On a more institutional level, the Arab League only convened an "emergency meeting" when Mubarak had already resigned and the staunch support expressed to Mubarak by the major states in the region weakened the potential impact of any decision by the League.

Because of the sheer pace at which the revolts unfolded, the Arab spring challenged the often problematic and overly complex consultation procedures underpinning the decision-making processes of most regional organisations, especially in Africa. Moreover, like other global events and power shifts in the international arena, the uprisings cast a dark light on the legitimacy and effectiveness of these regional organisations in so far as they failed to protect their own citizens and acted more like guardians of "incumbent regimes" than guarantors of fundamental human rights.

\section{Building regions from below: regionalism 2.0}

Most contributors have reflected upon the contribution that ideas and values have on the definition of regional models and goals. According to Langenhove, "the concept of 'region' is a discursive tool identifying a myriad of experiments, processes and projects". Regions may have many different meanings. They may refer to polities beyond the nation state or even below the nation state, as is the case with regional entities such as Flanders in Belgium. Moreover, the geographic scope of regions is not simply a given, but is fundamentally shaped by political, social and cultural discourses. What a region is and what it is not is the outcome of communicative interaction across generations and countries. In this respect, regionalism is not just an institutional phenomenon; at a more fundamental level, it must be seen as a socially constructed process.

The role of ideas and discourses is also fundamental for understanding the propagation of certain models of regionalism across the world. In Acharya's words, "regions produce and transmit their own ideas and images about other regions" and the world at large. As a consequence, scholars "must also look at how regions create, borrow, localise and repatriate ideas/norms as well as practices". Such a diversified approach opens new avenues for comparative research not only among regions of all sorts (from the sub-national to the supranational) but also between regions and states. According to Van Langenhove, more studies in this field "would not only contribute to a better understanding of the present world order but they would also help us rethink the state-centric approach still dominating our vision of global politics".

But if ideas and values matter in defining regions and, by default, in the adoption of each specific model of regionalism, whose ideas matter the most? What are the prevailing interests behind certain models of region building? In his analysis of Asian regionalism, Camroux maintains that "concepts such as 'region', 'regionalism' and the concomitant notions of 'community', with either a small 
or capital 'c', may very well be discursive subterfuges for promoting multilateral relations within a porous Asia". In his view, the growing centrality of China is fundamental to understanding how the regionalism agenda is being shaped and deciphering, underneath the rhetorical surface, what regional cooperation and integration really mean in Asia. Malamud and Gardini argue that regionalism has "peaked" in the political rhetoric of Latin American leaders and that, for all intents and purposes, regional cooperation has thus far aimed at strengthening incumbent executives, often at the expense of other voices. Strong presidents have also led the regionalism agenda in Africa, often to serve their own interests and advance their democratic credentials, while significant demands for public accountability, responsiveness and sustainable development have been overlooked.

Looking at judicial integration in Europe, Daniela Piana raises a similar point when she argues that, in a collective space where decisions taken in one country should be recognised as valid in others, mutual knowledge and reciprocal trust are fundamental preconditions not only for effectiveness, but also for legitimacy and accountability. In this regard, broader consultation involving civil society should complement the current elite-driven approach to judicial socialisation: "After all, the final good to be protected is the security and fundamental rights of citizens. They should have a say in the way such a good is ensured across domestic European borders."

Thus far, most scholars and observers have traditionally looked at regionalism as a politically neutral phenomenon in international affairs. Research in this field has been generally restricted to the 'quantity' of regionalism, rather than its 'quality'. Whether it is to explain the gradual devolution of authority from nation states to supranational institutions (as is the case with neo-functionalism) or whether it is to demonstrate the continuous bargaining process involving national governments (as is the case with intergovernmentalism), mainstream approaches to regional cooperation and integration have refrained from looking at the quality of these processes. ${ }^{6}$ Yet, the dynamic evolutions of a changing world force us to assess the state of regionalism not only in terms of its predominance and diffusion, but also and more importantly - in terms of how it contributes, if at all, towards the wellbeing of our societies. As a matter of fact, regionalism processes have been driven almost exclusively by political and economic elites, often through highly technocratic institutional arrangements. Although this may have been a necessary condition to help regional cooperation and integration processes 'take off, the evolution of regionalism in contemporary affairs increasingly calls into question the sustainability of an elite-driven model.

Citizens have been the underdogs of regionalism. From Europe, to Africa, Asia and Latin America, civil society has largely been on the receiving end of

${ }^{6}$ Haas, "The Study of Regional Integration"; Moravcsik, "Preferences and Power in European Community". 
region-building processes. More often than not, civil society has been intentionally sidelined, while some sympathetic non-governmental organisations have been given the instrumental task of supporting institutions in their efforts at building a regional 'identity'. In spite of rhetorical references to the importance of civic participation, regionalism has largely developed 'without the citizens'. As discussed throughout this issue, most 'models' and 'practices' of regionalism have tended to exclude the diversity of voices and roles in society. They have often served the specific interests of ruling elites (as in Latin America and Africa), the ambitions of hegemonic actors (as in Europe and Asia) or the agendas of industrial and financial powers. Moreover, through their apparently neutral technocratic character, most attempts at regional cooperation and integration have aimed to obscure the fact that there are always winners and losers in regionalism processes.

This top-down model is being increasingly challenged. Overlapping crises and the redistribution of power at the global level call into question the capacity of regions to deliver on their promises, thus unveiling the unavoidable political character of any model of regionalism. In response to the growing cost of regionalism, citizens want to have more say over future regional trajectories and exercise their democratic powers. As a consequence, regionalism is evolving from a 'closed' process, designed and packaged by a small circle of political and economic elites, to an 'open' process, in which democratic participation and accountability are playing an ever more important role. Borrowing from the jargon of Internet users, one may say that regions are transitioning from a 1.0 phase dominated by technocrats to a 2.0 stage characterised by horizontal networks, alternative models and citizens' contestations.

The EU, undoubtedly the most advanced and successful example of regionalism in the world, is now experiencing the direst consequences of such a transition. Amid rising unemployment, social malaise and growing discontent for the lack of accountability of national and regional politics, millions of citizens have been protesting against the Union and its political and economic agenda. Contrary to what eurosceptics would have us believe, these citizens do not call for less Europe: they want a different Europe. ${ }^{7}$ They would like regional integration to be more about connecting cultures and individuals and less about supporting capital. They would like their regional institutions to focus on helping the unemployed rather than bailing out bankrupt banks. They would like to see more solidarity across classes and generations, rather than less. They would like cooperation to be about building a different future instead of reshuffling old ideas. The future of regionalism may very well entail a growing 'politicisation' of regions, whereby citizens and civil society demand more voice and power in influencing not just general principles and values, but also the long-term political trajectories of their regions.

${ }^{7}$ For an example, see the debate on "The Road to Europe", http://www.opendemocracy.net. 


\section{References}

Fawcett, L. "Regionalism in Historical Perspective". In Regionalism in World Politics: Regional Organisation and International Order, edited by L. Fawcett and A. Hurrell. Oxford: Oxford University Press, 1995.

Haas, E. "The Study of Regional Integration: Reflections on the Joy and Anguish of Pretheorizing". International Organization 24, no. 4 (1963): 606-46.

Katzenstein, P. A World of Regions. Asia and Europe in the American Imperium. New York: Cornell University Press, 2005.

Moravcsik, A. "Preferences and Power in the European Community: A Liberal Intergovernmentalist Approach". Journal of Common Market Studies 31, no. 4 (1993): 473-524.

Van Langenhove, L. Building Regions. The Regionalization of the World Order. Farnham: Ashgate, 2011.

Warleigh-Lack, A., N. Robinson and B. Rosamond. New Regionalism and the European Union. Dialogues, Comparisons and New Research Directions. London and New York: Routledge, 2011. 